\title{
A major impact of the influenza seasonal epidemic on intensive care units, Réunion, April to August 2016
}

L Filleul 1 , DB Ranoaritiana ${ }^{23}$, E Balleydier ${ }^{1}$, D Vandroux 4 , C Ferlay ${ }^{5}$, M Jaffar-Bandjee 6 , J Jaubert ${ }^{7}$, B Roquebert ${ }^{6}$, B Lina ${ }^{8}$, $M$ Valette ${ }^{8}$, B Hubert ${ }^{9}, S$ Larrieu ${ }^{1}$, E Brottet ${ }^{1}$

1. Santé publique France, French national public health agency, Regional unit (Cire) Océan Indien, Réunion, France

2. Indian Ocean Field Epidemiology Training Programme, Surveillance des Epidémies et Gestion des Alertes (SEGA) One Health Network, Indian Ocean Commission, Mauritius

3. Epidemiological Surveillance Department, Ministry of Health, Madagascar

4. Intensive Care Unit, Centre Hospitalier Universitaire, Saint-Denis, Réunion, France

5. Intensive Care Unit, Centre Hospitalier Universitaire, Saint-Pierre, Réunion, France

6. Laboratory of virology, Centre Hospitalier Universitaire, Saint-Denis, Réunion, France

7. Laboratory of biology, Centre Hospitalier Universitaire, Saint-Pierre, Réunion, France

8. Hospices Civils de Lyon, National Influenza Centre, Laboratory of Virology \& Virpath, CIRI, Inserm U1111, CNRS UMR5308, ENS Lyon, UCBL, Lyon, France

9. Santé publique France, French national public health agency, Regional unit (Cire) Pays de la Loire, Nantes, France

Correspondence: Laurent Filleul (laurent.filleul@ars.sante.fr)

Citation style for this article:
Filleul L, Ranoaritiana DB, Balleydier E, Vandroux D, Ferlay C, Jaffar-Bandjee M, Jaubert J, Roquebert B, Lina B, Valette M, Hubert B, Larrieu S, Brottet E. A major impact of the influenza seasonal epidemic on intensive care units, Réunion, April to August 2016. Euro Surveill. 2016;21(47): pii=30405. DOI: http://dx.doi. org/10.2807/1560-7917.ES.2016.21.47.30405

Article submitted on 25 October 2016 / accepted on 23 November 2016 / published on 24 November 2016

The 2016 seasonal influenza in Réunion in the southern hemisphere, was dominated by influenza $A\left(\mathrm{H}_{1} \mathrm{~N}_{1}\right)$ pdmo9 (possibly genogroup 6B.1). An estimated 100,500 patients with acute respiratory infection (ARI) consulted a physician (cumulative attack rate $11.9 \%$ ). Sixty-six laboratory-confirmed cases (65.7/100,000 ARI consultations) were hospitalised in an intensive care unit, the highest number since 2009. Impact on intensive care units was major. Correlation between severe cases was 0.83 between Réunion and France and good for 2009 to 2015.

Réunion is a southern hemisphere French overseas territory with 843,529 inhabitants (2015 estimate [1]) located in the Indian Ocean between Madagascar and Mauritius. The island benefits from a healthcare system similar to mainland France. In the 2016 influenza season lasting from April to August, Réunion experienced a high number of severe influenza cases.

\section{Influenza surveillance system and definition of severe cases}

Influenza is monitored through a multi-source surveillance system including a sentinel general practitioners (GPs) network, hospital emergency departments, intensive care units (ICUs), laboratory and mortality data [2]. The sentinel GPs network [3] is based on reports from 53 volunteer GPs located throughout the island. They report on weekly basis to the regional office of the French national public health agency (Cire OI) their total number of consultations and number of consultations for acute respiratory infections (ARI) (defined as a sudden onset of fever $\left(\geq 38^{\circ} \mathrm{C}\right)$ and cough, which are associated or not with other symptoms, such as for example breathing difficulty or headache). In addition to the weekly proportion of ARI among sentinel consultations, a weekly estimated number of ARI consultations is extrapolated from the total number of consultations in Réunion which are derived from health insurance data. Severe cases of influenza are reported in real-time by clinicians of ICUs to the Cire OI. A severe influenza case is defined as a patient with laboratoryconfirmed influenza (positive RT-PCR for influenza virus) admitted for more than 24 hours to an ICU.

\section{The 2016 influenza epidemic in Réunion}

In 2016, the influenza epidemic period in Réunion started one month earlier than usual (week 17, end of April) and ended in week 30 (Figure 1). The epidemic peak was reached at week 27 in July. During that week, the estimated number of consultations due to ARI was 8,700 . Over the whole epidemic period, the number of patients with ARI who consulted a GP was estimated at 100,500 which represents a cumulative attack rate of $11.9 \%(100,585 / 843,529)$ in the general population. At the beginning of the epidemic period, we observed mainly influenza B virus circulation, and after 6 weeks, influenza $A\left(\mathrm{H}_{1} \mathrm{~N}_{1}\right)$ pdmog virus became the predominantly circulating virus on the Island. We also detected some $\mathrm{A}\left(\mathrm{H}_{3} \mathrm{~N}_{2}\right)$ viruses but they accounted for only $20 \%$ of influenza viruses identified through surveillance. Influenza B virus strains were those targeted by the 2016 seasonal vaccine for the southern hemisphere (B/ Victoria) [4]. 


\section{FIGURE 1}

Severe influenza cases by virus type and death, Réunion, France, week 1 to week 35, $2016(n=66)$

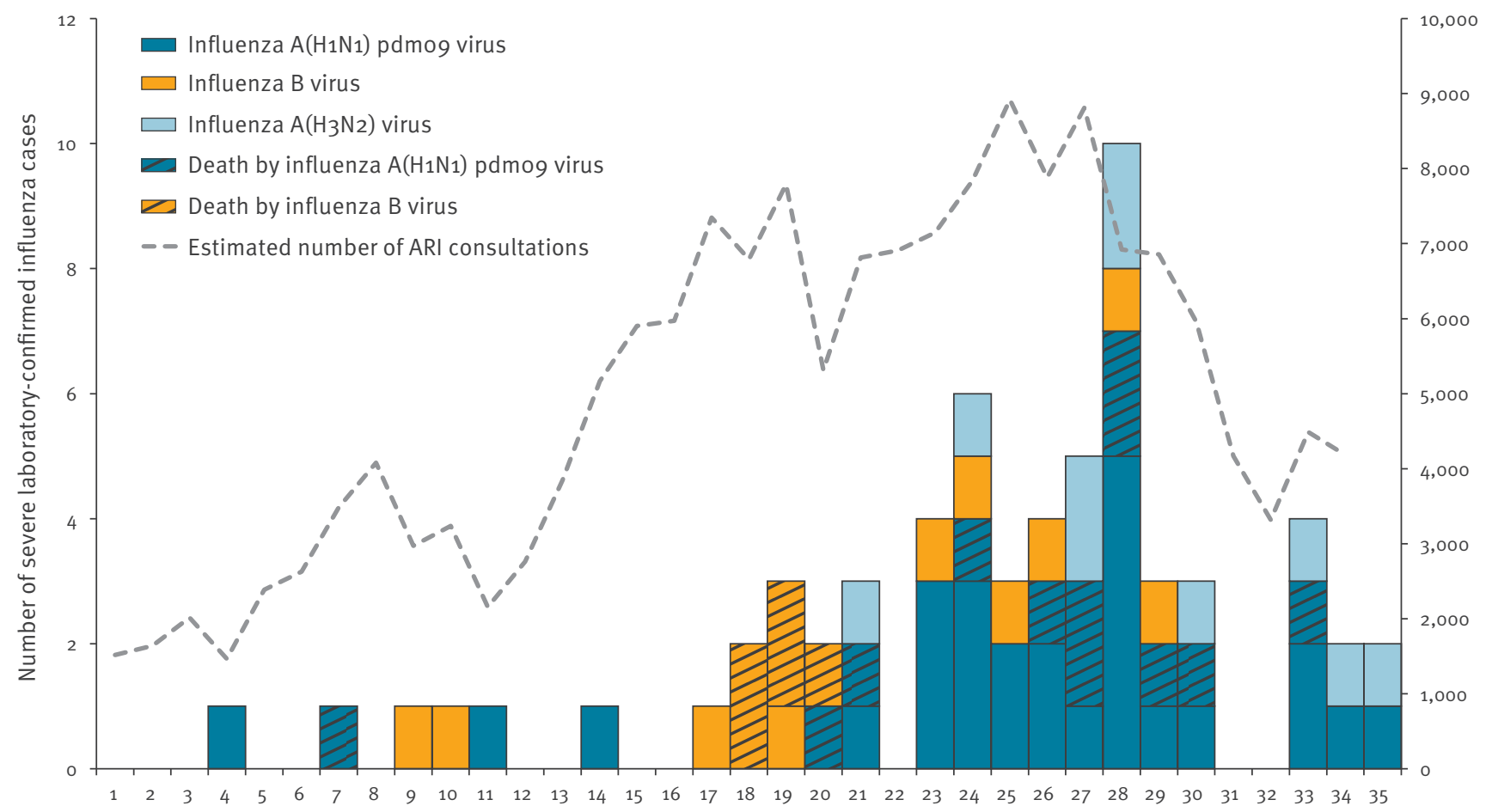

Week of intensive care unit admission (2016)

ARI: acute respiratory infections.

${ }^{a}$ Extrapolated from the total number of consultations in Réunion, which were derived from health insurance data.

\section{TABLE}

Characteristics of severe influenza cases, Réunion, influenza season $2016(\mathrm{n}=66)$

\begin{tabular}{|c|c|c|c|}
\hline Influenza virus types/subtypes & $\begin{array}{l}A\left(\mathrm{H}_{1} \mathrm{~N}_{1}\right) \mathrm{pdmog} \\
(\mathrm{n}=40)\end{array}$ & $\begin{array}{c}B \\
(n=15)\end{array}$ & $\begin{array}{l}\mathrm{A}\left(\mathrm{H}_{3} \mathrm{~N}_{2}\right) \\
(\mathrm{n}=11)\end{array}$ \\
\hline Sex (Male / Female) & $25 / 15$ & $8 / 7$ & $4 / 7$ \\
\hline Median age in years (range) & $54 \cdot 5(0-76)$ & $55(21-86)$ & $48(13-76)$ \\
\hline \multicolumn{4}{|l|}{ Risk factors } \\
\hline Age $\geq 65$ years & 10 & 3 & 3 \\
\hline Age $<1$ year & 2 & 0 & 0 \\
\hline Chronic respiratory disease & 15 & 5 & 8 \\
\hline Diabetes & 9 & 3 & 3 \\
\hline Cardiac disease & 5 & 2 & 0 \\
\hline Neuromuscular disease & 3 & 2 & 0 \\
\hline Obesity (Body mass index > 30 ) & 6 & 2 & 0 \\
\hline Pregnancy & 2 & 1 & 1 \\
\hline Immunodeficiency & 3 & 0 & 0 \\
\hline None & 2 & 3 & 1 \\
\hline \multicolumn{4}{|l|}{ Indicators of signs of severity } \\
\hline Median Simplified Acute Physiology Score II (SAPS II) (range) & $37.5(16-95)$ & $46.0(17-101)$ & $45.0(21-65)$ \\
\hline Respiratory assistance: & 25 & 12 & 9 \\
\hline - with acute respiratory distress syndrome (ARDS) & 19 & 9 & 8 \\
\hline $\begin{array}{l}\text { - with ARDS needed extracorporeal membrane oxygenation } \\
\text { (ECMO) }\end{array}$ & 5 & 1 & 2 \\
\hline Death & 13 & 5 & 0 \\
\hline \multicolumn{4}{|l|}{ Influenza vaccination } \\
\hline Unvaccinated & 34 & 11 & 8 \\
\hline Vaccinated & 2 & 1 & 2 \\
\hline Not specified & 4 & 3 & 1 \\
\hline
\end{tabular}


FIGURE 2

Severe influenza cases by age group and virus type/ subtype, Réunion, France, week 1 to week 35, $2016(n=66)$

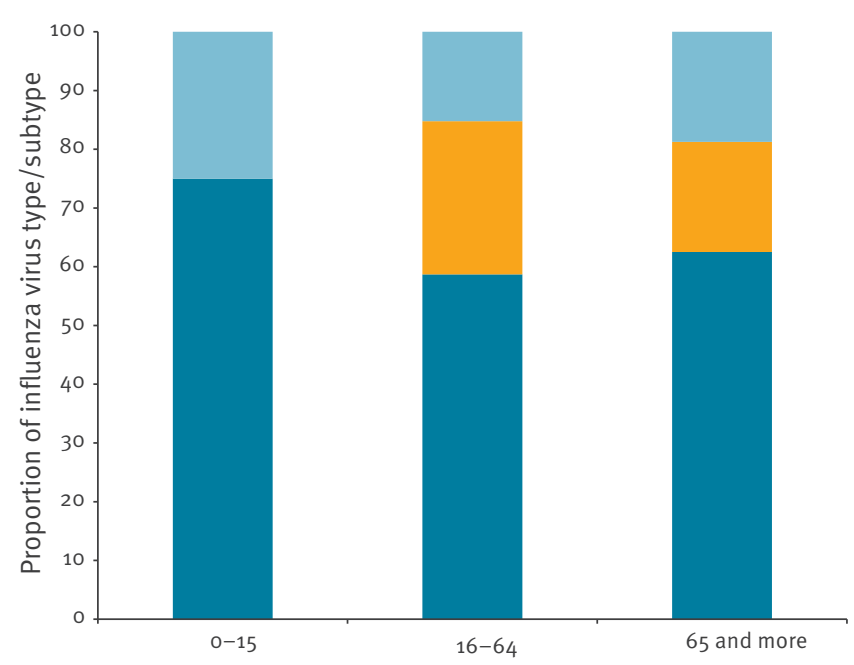

Age group (years)

$$
\begin{array}{lll}
\mathrm{A}\left(\mathrm{H}_{3} \mathrm{~N}_{2}\right) & \mathrm{B} & \mathrm{A}\left(\mathrm{H}_{1} \mathrm{~N}_{1}\right) \mathrm{pdmog}
\end{array}
$$

Between January and August 2016, 66 laboratory-confirmed influenza cases with severe disease were identified: 15 (23\%) were infected with influenza B virus, 11 $(17 \%)$ with $A\left(\mathrm{H}_{3} \mathrm{~N}_{2}\right)$ and $40(61 \%)$ with $\mathrm{A}\left(\mathrm{H}_{1} \mathrm{~N}_{1}\right)$ pdmog. The first virological analyses from the French national influenza reference centre in Lyon, France (sequencing ongoing), identified $\mathrm{A}\left(\mathrm{H}_{1} \mathrm{~N}_{1}\right)$ pdmog possibly related to genogroup 6B.1 in eight cases from surveillance and in seven severe cases infected by influenza $A\left(\mathrm{H}_{1} \mathrm{~N}_{1}\right)$ pdmog virus.

The incidence rate of severe cases over the whole season was 65.7 per 100,000 ARI consultations in 2016, higher (1.5 times) than that observed in 2014 (46.0/100,000), and the highest observed since the start of surveillance in 2009 [5]. When only the epidemic period was considered, the incidence in 2016 was 51.7 per 100,000 vs 31.7 per 100,000 in 2014 .

Median age of the 66 severe cases was 53.5 years (range: one month to 86 years). We did not observe any trend in the distribution of influenza virus types according to age among severe cases (Figure 2), nevertheless, the majority of cases were aged over 41 years $(52 / 66)$ irrespective of the incriminated viruses. Sex ratio $(M / F)$ was $1.27(37 / 29)$.

Medical characteristics of patients are presented in Table. Among the 66 cases, 46 (70\%) required mechanical ventilation, and of them 36 presented signs and symptoms compatible with criteria for acute respiratory distress syndrome (ARDS) using the Berlin ARDS definition [5]. Eight of 36 needed extracorporeal membrane oxygenation (ECMO). The case fatality ratio was $27 \%, 18$ of 66 patients died. Median of Simplified
Acute Physiology Score II (SAPS II) score was 47.6 (range: 16-101). Regarding risk factors (Table), 60 cases had risk factors including chronic respiratory disease $(n=28)$, age $\geq 65$ years $(n=16)$ and diabetes $(n=15)$. Of 58 severe cases where the vaccination status was known, 53 were unvaccinated.

\section{Correlation between number of severe influenza cases in Réunion and mainland France}

When we compared trends in the number of severe cases in Réunion and mainland France using data from the national influenza surveillance system over the past influenza seasons, we observed a good correlation between them [6]. During the years 2009 to 2015 , regardless of circulating virus types or subtypes, the Pearson's correlation coefficient between number of severe cases in Réunion and mainland France was 0.83 . For each increase in the number of cases in ICU observed in Réunion, the next season in mainland France was also characterised by an increase in severe influenza cases (Figure 3).

\section{Discussion}

The 2016 influenza epidemic period on Réunion was characterised by an unusual duration of 14 weeks compared to a mean of 8 weeks in previous years [7]. Severe cases in ICUs were mainly related to influenza $A\left(\mathrm{H}_{1} \mathrm{~N}_{1}\right)$ pdmog virus infections. Compared with 2014, we observed twice the number of severe influenza cases in 2016 and it was three times that of other previous years. However, we did not observe an increased case fatality ratio compared with previous years.

Individual factors did not allow us to infer causes for this high number of cases, since we found common risk factors for influenza such as chronic respiratory disease, diabetes, cardiac disease or age. In this respect, we did not observe any significant differences between previous seasons or type/subtype of viruses [7].

The characterisation of circulating viruses showed that influenza $B$ and influenza $A\left(N_{1} N_{1}\right)$ pdmog viruses were similar to the strains included in the 2016 southern hemisphere seasonal influenza vaccine, used in Réunion [4]. Worldwide, two genetic subclades of viruses within the $6 \mathrm{~B}$ clade have emerged, designated as subclades: 6B.1 defined by $\mathrm{HA}_{1}$ amino acid substitutions $\mathrm{S}_{162} \mathrm{~N}$ and $\mathrm{I}_{216 \mathrm{~T}}$ and $6 \mathrm{~B} .2$ defined by HA1 amino acid substitutions $\mathrm{V}_{152} \mathrm{~T}$ and $\mathrm{V}_{173} \mathrm{I}$ [8]. Chambers et al. showed that the vaccine provided significant protection against $\mathrm{A}\left(\mathrm{H}_{1} \mathrm{~N}_{1}\right)$ pdmog illness despite genetic evolution in circulating viruses [9].

The influenza immunisation coverage among the target population (age $>65$ years old, chronic diseases, pregnant women) is low in Réunion (around 34\% in 2016), and this was confirmed by our data where a minimum of 53 severe cases were not vaccinated and 60 cases had risk factors. While the low immunisation coverage could explain the severity of the outbreak, it is 


\section{FIGURE 3}

Number of severe influenza cases in mainland France and in Réunion by influenza seasons, 2009-2016

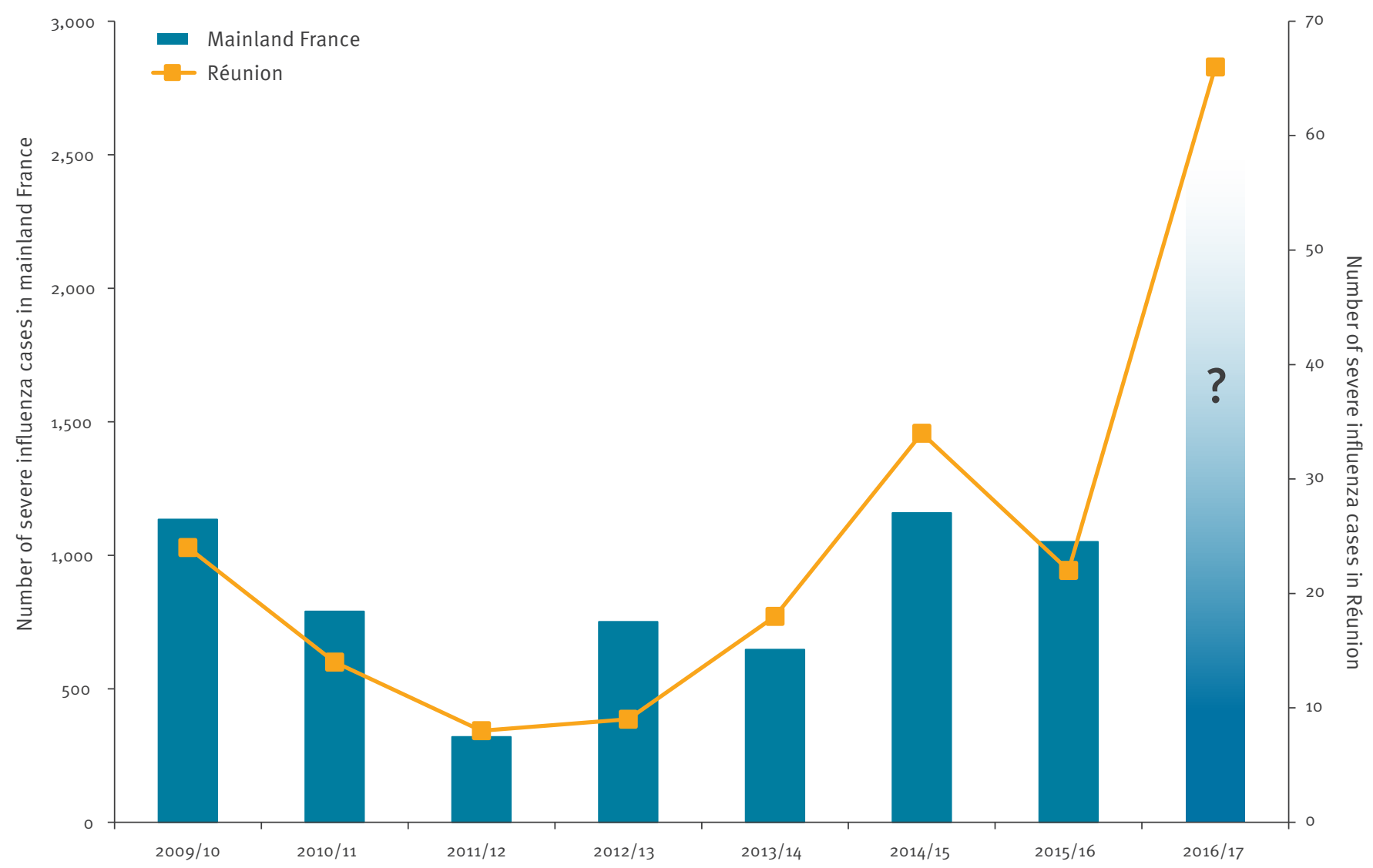

Influenza seasons

Influenza seasons labelled for the northern hemisphere. The corresponding southern hemisphere seasons are $2009,2010,2011$ etc.

The northern hemisphere influenza season has started only recently and numbers of severe cases are not yet available. If a similar situation to that in Réunion happened during the 2016/17 influenza season in mainland France and potentially other European countries, we might observe an increase of severe influenza cases.

not sufficient to explain the unusual number of severe cases since immunisation coverage was already low during the past few years.

Our data showed a major impact on public health of the 2016 influenza epidemic in terms of influenzarelated morbidity and incidence of severe cases requiring treatment in ICUs, but not for case fatality [7]. The demonstrated correlation between severity of cases in different seasons in Réunion and mainland France is based on the data observed and not the result of a modelling exercise. This fact should be taken in consideration. Future studies should confirm the pattern and the conclusions that can be drawn from the impact of influenza seasons on ICUs in Réunion for the situation in the following influenza season in France.

If a similar situation to that in Réunion happened during the 2016/17 influenza season in mainland France and potentially other European countries, we might observe an increase of severe influenza cases. This information can be useful to strengthen prevention i.e. by improving immunisation coverage for the 2016/17 season and to prepare ICUs to be able to care for possibly more influenza patients than usual.

\section{Acknowledgements}

We acknowledge all the sentinel general practitioners of Réunion, the emergency departments of Réunion, the microbiology laboratory of the University Hospital Centre of Saint-Denis, the National Reference Centre for influenza, the National Health Insurance Centre of Réunion, and the Health Agency of Indian Ocean.

\section{Conflict of interest}

None declared. 


\section{Authors' contributions}

All authors contributed to the interpretation of the results, the revision of the draft manuscript and approved the final version. LF wrote the manuscript; $\mathrm{DBR}$ and $\mathrm{EBr}$ conducted the data analysis; DBR, EBa, SL and BH contributed to the epidemiological analyses and to the writing of the manuscript. DV and CF were involved in the data collection in ICU; MCJB and JJ were responsible for the viral laboratory analyses; $\mathrm{BL}$ and $M V$ were involved in the characterization of viruses. $\mathrm{EBr}$ was involved in the design of the influenza surveillance system and participated in the writing of the manuscript.

\section{References}

1. Institut national de la statistique et des études économiques (Insee). Évolution de la population totale au 1er janvier 2015. [Estimates of the total population as of 1 January 2015]. Paris: Insee; 2015. French. Available from: http://www.insee.fr/fr/ themes/detail.asp?ref_id=estim-pop\&reg_id=99

2. Filleul L, Brottet E, Gauzere B, Winer A, Vandroux D, Michault $A$, et al. Reunion, a sentinel territory for influenza surveillance in Europe. Euro Surveill. 2012;17(27):20212.PMID: 22790605

3. Brottet E, Jaffar-Bandjee MC, Rachou E, Polycarpe D, Ristor $B$, Larrieu S, et al. Sentinel physician's network in Reunion Island: a tool for infectious diseases surveillance. Med Mal Infect. 2015;45(1-2):21-8. DOI: 10.1016/j.medmal.2014.11.004 PMID: 25575412

4. World Health Organization (WHO). Recommended composition of influenza virus vaccines for use in the 2016 southern hemisphere influenza season. Geneva: WHO; 24 Sep 2015. Available from: http://www.who.int/influenza/vaccines/virus/ recommendations/en/

5. Ranieri VM, Rubenfeld GD, Thompson BT, Ferguson ND, Caldwell E, Fan E, et al., ARDS Definition Task Force. Acute respiratory distress syndrome: the Berlin Definition.JAMA. 2012;307(23):2526-33.PMID: 22797452

6. Institut de Veille Sanitaire (InVS). Bulletin épidémiologique grippe. [Epidemiological bulletin on influenza]. 27 April 2016. Saint-Maurice: InVS. French. Available from: http://invs. santepubliquefrance.fr/Dossiers-thematiques/Maladies infectieuses/Maladies-a-prevention-vaccinale/Grippe/ Grippe-generalites/Donnees-de-surveillance/Archives/ Bulletin-epidemiologique-grippe.-Point-au-27-avril-2016

7. Brottet E, Vandroux D, Gauzere BA, Antok E, Jaffar-Bandjee MC, Michault A, et al. Influenza season in Réunion dominated by influenza $B$ virus circulation associated with numerous cases of severe disease, France, 2014. Euro Surveill. 2014;19(39):20916. DOI: 10.2807/1560-7917. ES2014.19.39.20916 PMID: 25306979

8. European Centre for Disease Prevention and Control (ECDC). Influenza virus characterisation, summary Europe, May 2016. Stockholm: ECDC; 2016. Available from: http://ecdc.europa.eu/ en/publications/Publications/influenza-virus-characterisationmay-2016.pdf

9. Chambers C, Skowronski DM, Sabaiduc S, Winter AL, Dickinson JA, De Serres G, et al. Interim estimates of 2015/16 vaccine effectiveness against influenza $\mathrm{A}\left(\mathrm{H}_{1} \mathrm{~N}_{1}\right)$ pdmo9, Canada, February 2016. Euro Surveill. 2016;21(11):30168. DOI: 10.2807/1560-7917.ES.2016.21.11.30168 PMID: 27020673

\section{License and copyright}

This is an open-access article distributed under the terms of the Creative Commons Attribution (CC BY 4.0) Licence. You may share and adapt the material, but must give appropriate credit to the source, provide a link to the licence, and indicate if changes were made.

This article is copyright of the authors, 2016. 